\title{
Simulation application of ALC external wall panel on rigid column frame brace system
}

\author{
Xiujuan $\mathrm{Lv}^{1}$, Wuxin $\mathrm{Chen}^{2, *}$, and Xuguang $\mathrm{Li}^{3}$ \\ ${ }^{1}$ Department of Civil Engineering, Henan Technical College of Construction, Zhengzhou, China \\ ${ }^{2}$ College of Engineering and Architecture, Henan University of Technology, Zhengzhou, China \\ ${ }^{3}$ CSCEC Science \& Technology Henan Co., Ltd., Zhengzhou 450000, China
}

\begin{abstract}
Taking a building under construction as an example, based on ABAQUS software, studies the failure mode, hysteretic curve, displacement ductility and energy consumption capacity of ALC external wall panel under three working conditions of assembled stiffened column frame brace system, assembled frame system and cast-in-place frame system. The simulation results show that:1.Under the action of low cycle load, the assembled stiffened column frame support system has no damage,the maximum stress value is 6.98 $\mathrm{MPa}$, which is located at the position of steel plate at the column bottom; 2.Under the condition of ALC hanging wall plate, the structure ductility is better; 3.Part of the energy consumption is borne by the light material hanging wall plate, and the stiffened column frame support system has higher energy consumption capacity. The assembled ALC external wall panel based on the rigid column frame support system has better mechanical performance, can significantly improve the energy consumption capacity of the overall structure, and has high construction feasibility,economy and engineering application value.
\end{abstract}

\section{Introdution}

The composite beam and column structure with assembled stiffening columns is a new type of assembled structure system independently developed by China Construction Seventh Engineering Bureau Co., Ltd. Scholars at home and abroad have carried out some research on it, such as Jiao Anliang ${ }^{[1]}$, Zhang Ailin ${ }^{[2]}$, Li Guoqiang ${ }^{[3]}$ and Lujiasen ${ }^{[4]}$ et al.

But till now, there is no research on the simulation application of ALC external wall and external wall panel based on the rigid column frame support system in China. For this reason, this paper puts forward the research on the numerical simulation application of the assembled ALC external wall and external wall panel based on the rigid column frame support system, which provides some reference for the later design, production and construction.

\footnotetext{
* Corresponding author: chenwx@haut.edu.cn
} 


\section{Project overview}

The project is a comprehensive building of China Construction Technology Henan Co., Ltd. with an annual output of 1 million $\mathrm{m}^{2}$ prefabricated component construction project. It is located in the southwest corner of the intersection of Yunan street and Yuzhong Road, Quliang Town, Xinmi City. The bottom floor of the building is $67.2 \mathrm{~m}$ long, $35.1 \mathrm{~m}$ wide, $16.8 \mathrm{~m}$ high and 4 floors above the ground. The structure is a composite beam frame structure with fabricated rigid columns, with seismic fortification intensity of 7 degrees.

The maximum span of the complex building is $7.2 \mathrm{~m}$, the height of the first floor is 5.1 $\mathrm{m}$, and the height of the second to fourth floors is $3.9 \mathrm{~m}$. the external wall adopts the horizontal strip board system ALC external hanging wall board. In this paper, the size of ALC external wall panel is $6000 \mathrm{~mm} \times 2500 \mathrm{~mm} \times 150 \mathrm{~mm}$, the section of stiffening column is 400 $\mathrm{mm} \times 400 \mathrm{~mm}$, and the section of frame beam is $200 \mathrm{~mm} \times 400 \mathrm{~mm}$. All beams and columns are made of $\mathrm{C} 30$ concrete, and the outer side of the rigid column is covered with $50 \mathrm{~mm}$ thick fine aggregate concrete. See Figure 1 and Figure 2 for details.



Fig. 1. Overall effect diagram.

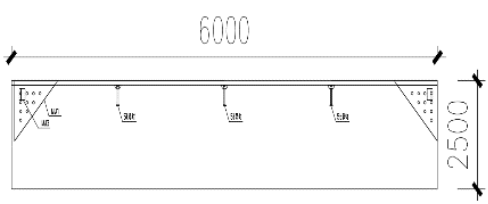

Fig. 2. External wall panel.

\section{Establishment of finite element model}

Three models of cast-in-place structure, assembled frame structure and assembled stiff column structure are established. Based on the three models, the influence of external wall panel on the overall frame is analyzed. See Table 1 for model information.

Table 1. Model information.

\begin{tabular}{ccc}
\hline Model number & With or without External wall panel & Structural form \\
\hline A & with & Rigid column frame bracing system \\
B & with & Assembled frame system \\
C & without & Frame structure system \\
\hline
\end{tabular}

\subsection{Unit type and material properties}

Based on ABAQUS, C3D8R element is selected for concrete and steel column element types.T3D2 element is selected for reinforcement element types. In the grid division, the concrete and steel column elements are distributed with 0.1 spacing, and the reinforcement elements are distributed with 0.01 spacing. All contacts in this paper are selected according to tie contact.

\subsection{Boundary conditions and loads}

The boundary conditions $\mathrm{U}_{1}, \mathrm{U}_{2}, \mathrm{U}_{3}, \mathrm{R}_{1}, \mathrm{R}_{2}, \mathrm{R}_{3}$ are set to 0 at the bottom of the stiff column. The whole model is subject to gravity load. In order to make the model calculation results faster, displacement loading is adopted for the model. The loading system is controlled by $0.25 \Delta_{\mathrm{y}}, 0.5 \Delta_{\mathrm{y}}, 0.75 \Delta_{\mathrm{y}}, \Delta_{\mathrm{y}}, 2 \Delta_{\mathrm{y}}, 3 \Delta_{\mathrm{y}}, 4 \Delta_{\mathrm{y}}, 5 \Delta_{\mathrm{y}}, 6 \Delta_{\mathrm{y}}, 7 \Delta_{\mathrm{y}}$. 


\section{Analysis of simulation results}

The failure mode, hysteretic curve, ductility and energy consumption capacity, are compared and analyzed, under the condition of model A,B and C.

\subsection{Failure mode}

Model A is not damaged, stress value is $6.98 \mathrm{MPa}$, which appears at the position of steel plate, at the bottom of the column. Model B is damaged, the maximum stress value is $2.25 \mathrm{MPa}$, which appears in the concrete column. Under the action of horizontal seismic force, the maximum stress value exceeds the tensile strength of C30 concrete, and the concrete column is damaged. Under the condition of model $\mathrm{C}$, the joint position of beam column is damaged. See Figure 3 for details.

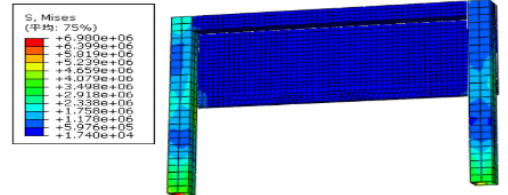

(a) Stress nephogram of model A

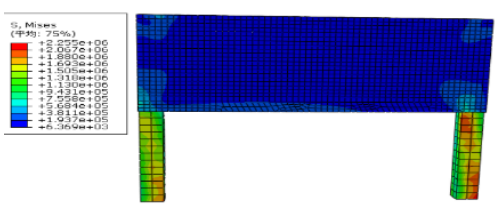

(b) Stress nephogram of model B



(c) Stress nephogram of model C

Fig. 3. Stress nephogram.

\subsection{Hysteresis curve}

The hysteresis curves of the three models in Figure 4 are compared and analyzed.

1) In the initial stage of displacement loading, the hysteretic curve of model $A$ is shuttle shaped. With the increase of displacement loading, the hysteresis curve appears a slight "pinching" phenomenon. It is assumed that there is no small slip between the steel and the concrete, or the phenomenon of "pinching" of the structure should be increased.

2) The hysteretic curve of model B at the initial stage of loading is also shuttle shaped, but with the increase of loading displacement, the phenomenon of "pinching" is intensified due to the small displacement constraint of reinforced concrete column.

3) Since no external wall panel is added to model C, all loads are borne by frame beams and columns, and the hysteretic curve is in the shape of bow.

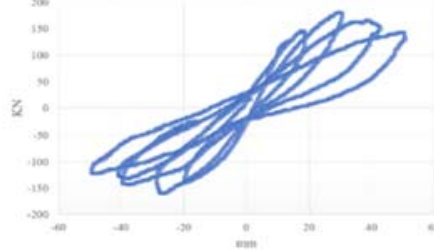

(a) Hysteretic curves of model A

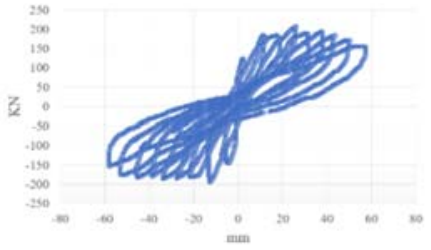

(b) Hysteretic curves of model B 




(c) Hysteretic curves of model C

Fig. 4. Hysteretic curves.

\subsection{Displacement ductility}

The ratio of displacement to yield displacement, where the ultimate displacement is $\Delta_{\mathrm{u}}$ and the yield displacement is $\mu$. Table 2 shows the displacement ductility comparison of three models.

Table 2. Comparison of displacement ductility coefficient.

\begin{tabular}{llll}
\hline Model & $\Delta_{u} / \mathrm{mm}$ & $\Delta_{y} / \mathrm{mm}$ & $\mu$ \\
\hline Model A & 115.41 & 16.75 & 6.89 \\
Model B & 101.41 & 18.54 & 5.47 \\
Model C & 82.10 & 25.26 & 3.25 \\
\hline
\end{tabular}

The ductility coefficients of model A and model B are higher than those of model C, which indicates that the ductility of the structure is better under the condition of the existence of external wall panels.

The energy consumption of model A and model B exceeded that of model C. In the later stage of loading, the energy consumption of model A is significantly higher than that of the other two structural systems, which indicates that ALC rigid column frame system has higher energy consumption capacity.

\section{Design suggestions}

Because the external wall panel is larger than the size specified in the Prefabricated Concrete External Wall Panel (16J110-2), so which requires special design, such as to add hidden beams and columns with a section of $150 \mathrm{~mm} \times 150 \mathrm{~mm}$ on the three sides respectively, and to shorten the stirrup spacing to $100 \mathrm{~mm}$, and to place double-layer steel mesh with 200mm spacing. As shown in Figure 5 for details.
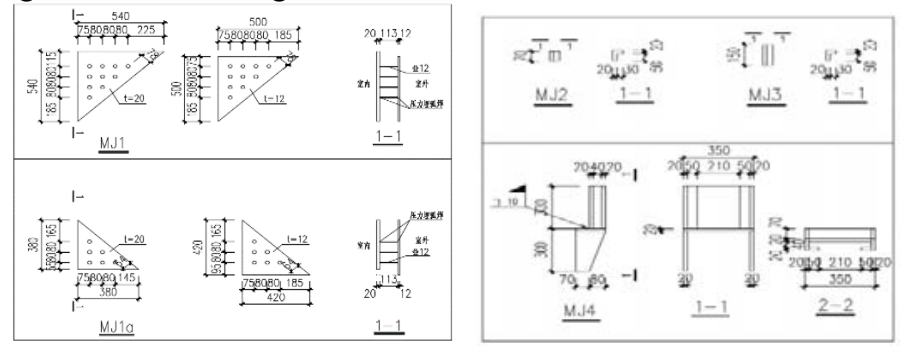

Fig. 5. The detailed design of node.

The hanging point shall be in accordance with the hanging point specified in the Technical Specification for Precast Frame Structure assembled by stiff-columns and Hybrid-beams(JGJ /T400-2017), since the size of components in this project is too large, the connection between ALC external hanging wall panel and hanging parts shall be designed 
separately. As a result, the embedded parts embedded in the external wall panel are composed of two triangular steel plates, and the middle part is welded with steel bars to form a whole, the stirrup at the corner of triangular steel plate is densified to $50 \mathrm{~mm}$, which are all beneficial for stress diffusion.

\section{Conclusions}

Under the action of low cycle load, model A has no damage, the maximum stress value is $6.98 \mathrm{MPa}$, which is located at the position of steel plate at the column bottom . Model B appeares the damage situation, when the maximum stress value is $2.25 \mathrm{MPa}$, which appeares in the concrete column. Under the action of horizontal seismic force, when the maximum stress value exceeds the tensile strength of $\mathrm{C} 30$ cast-in-place concrete, the concrete column of model $\mathrm{C}$ will be damaged and the joint position of beam column will be damaged.

The ductility coefficient of model A is $25.9 \%$ higher than that of model B. The ductility coefficients of model A and model B are higher than those of model C. In a word, under the condition of ALC hanging wall plate (model A), the structure ductility is better.

At the initial stage of cyclic load, the energy consumption of the three models is almost the same. In the middle period of loading, the energy consumption of model A began to increase compared with the other two models, and the energy consumption of model A and model B with external wall panels exceeded that of model C. At the later stage of loading, the energy consumption of model A is significantly higher than that of the other two structural systems. Model A has higher energy consumption capacity. The assembled ALC wall panel based on the rigid column frame support system has better mechanical performance, can significantly improve the energy consumption capacity of the overall structure, and has high construction feasibility, economy and engineering application value.

\section{Acknowledgement}

Fund Project: National key R \& D project: key technology and equipment for efficient hoisting and installation of components on construction site Project No.: $2017 \mathrm{yfc} 0703900$

About the author: LV Xiujuan (1973 -), female, graduate student, associate professor, mainly engaged in teaching research of construction.

\section{References}

1. Jiao Anliang, Li Zhengliang. Experimental study on seismic performance of rigid assembled frame core tube structure [J]. Vibration and impact, 2016,35 (2): 31-38

2. Zhang Ailin, Ma Lin, Liu Xuechun, et al. Finite element analysis of the mechanical performance of steel frame with prefabricated external wall panel [J]. Journal of architectural structure, 2016,37 (S1): 152-157

3. Li Guoqiang, Wang Cheng. Experimental study on hysteretic behavior of external and internal ALC wall panel steel frame structure [J]. Steel structure, 2005,20 (1): 52-56

4. Lu Jiasen, Zhou Chenggong, Zheng Zhenpeng. Analysis method of prefabricated external wall panel [J]. Chinese and foreign architecture, 2013 (1): 104-107

5. McMullin K, Ortiz M, Yarra S, et al. Static experimental testing to define forcedeformation relationships of precast concrete cladding building facade systems[C]. Reston, VA: Structural Engineering Institute of ASCE, 2014 